\title{
Concept in Light of Development and Ontogeny of Speech
}

\author{
Olga Gnevek*, and Mariya Musijchuk \\ Nosov Magnitogorsk State Technical University, 455000, Lenin Street, 38, Magnitogorsk city, Russian
}

\begin{abstract}
The study contains analysis of the notion "concept" in the context of L.S.Vygotsky's theory on interrelated development of thinking and speech, as well as the identified prospects of studying the types and kinds of concepts regarding their relation to the development level of the speech and thinking mechanism. The inadvisability to abandon the conceptual approach to concept studies is justified, as this approach ensures identifying the main ways and conditions to develop the higher, theoretical type of thinking and the content-related generalization of the accumulated experience related to it that is expressed in the language. The concept as presented herein is a cognitive instrument, a means to form a cognitive worldview in general and a sphere of concepts in particular. As mental images and projections ascend to notions, the affective part of the cognitive process is not lost but is "hidden" in the means of constructing notions that is revealed within the cognitive process. Concepts can be studied along from concepts-images to notions and from notions (including scientific categories) to mental images and projections. In our opinion, particular value here belongs to insights that uncover the specific nature of formation and development of the cognitive worldview.
\end{abstract}

\section{Introduction}

In many ways, cognitive linguistics has "grown out" from the cycle of psycho-linguistic studies concentrated on the content of the thinking and speech interrelation and identification of the consistent patterns of forming and developing the speech and thinking activity. Russian psycho-linguistics started with the systematic studies of Vygotsky who acknowledged the phenomenological essence of thinking and speech and the complementarity of their inter-development in the phylogenesis and ontogenesis [1]. Viewed in this way, the cognitive and linguistic worldviews of specific native speakers correlate as the general and the whole and not as phenomena that develop in parallel. There is a certain trend in cognitive linguistics to separate these phenomena and even to set them in opposition, thus we believe that it is appropriate to study the central notional units of cognitive linguistics within the psycholinguistic context.

The central notion of cognitive linguistics is the notion of "concept" that has replaced such competing definitions as "logoepistem" (Vereshchagin, Kostomarov, Burvikova), "linguoculturem" (Vorobyev), and "mythologem" (Lähteenmäki, Bazylev) [2]. Different scientific schools retranslate the notion "concept" in different ways reflecting different understanding of the process of assigning the lexicon of a specific language. To make the definition analysis process more substantive, one needs to remember how Vygotsky understood the speech development process in ontogenesis.

The psychologist believed that the process of thinking and speech inter-development was carried out as assigning a word in its nominative, then denotative, and then significative functions. Identifying the three main functions of a word suggests its usage in speech as a nomination, denotation, and signification. Nominations are understood as "names of things" associated with objects and phenomena of the world around us; denotation is understood as a subject of thought that reflects an object or phenomenon of the objective reality and constitutes that conceptual content which a language unit corresponds to; and signification is understood as the meaning that reveals the substantial features of the reality phenomenon that constitutes the content of the notion. A specific feature of the denotation is generalizing the essential features of the designatum, and a specific feature of the signification is recreating a phenomenon based on the essential features presented in the designatum. According to this understanding, a word is considered as a substitute of the "world of things", then as a precursor of a notion, in which the meaning of a word plays the main role, and a notion proper which captures the unity of links inherent to meanings. It is no coincidence that Vygotsky compared the process of acquiring a word in its main functions to the parallel development of complex, preconceptual and conceptual thinking.

Davydov further develops the theory of Vygotsky in the similar direction. The scientist is convinced that acquiring a word as a means of conscious systematization of the verbal and cogitative experience occurs in three forms of generalization: complex, formal logical and theoretical (conceptual) generalization [3]. These three forms of generalization correspond to the three types of thinking introduced by Vygotsky. Davydov develops the theory of notion as well, stating that a notion is a generalization of essential, specific and individual

*Corresponding author: gnevek.olga@yandex.ru 
features of designated objects and phenomena and that it contains a mental means of forming itself.

Zhinkin details the structure of the thinking and speech mechanism, which is a psycho-physiological basis of storing and developing the cognitive worldview. This mechanism is presented by two coordinated departments: a universal subject code that includes concepts of existing and accumulated experience, as well as relations to the process of accumulating and systematizing such experience, and a grammatical code that allows verbalizing the existing experience in speech. According to Zhinkin, a universal subject code as a language of thinking and of brain is neither completely discrete nor completely analogous to sensory capabilities; its individuality is distinguished by the always individual experience of developing the thinking and speech mechanism [4].

Studies of psycholinguists correspond to the point of view of Zimnyaya who established a logically transparent relationship between language, speech, and thinking. She states that speech acts as a way of forming and phrasing a thought, a language - as a means of that [5]. For communication practice, this means that everything that falls within the sphere of thinking and becomes an object of realization (consciousness) can and must be verbalized.

Within the context of cognitive science, a multidisciplinary endeavor combining gnoseology and the psycho-linguistic theory reveals the processes of forming a cognitive worldview. The cognitive worldview is understood as reflection of the surrounding world in the psyche of an individual through the prism of acquired experience. The world is perceived under the influence of personal perception and the perception formed within the context of the culture in which a person develops. In ontogenesis, an individual aims at objective perception of the surrounding reality and, consequently, aims at, ideally, acquiring a word as the denotation and signification, the content of which reflects actually existing interconnections and relations. In this meaning, a concept cannot be formed based on complex or undeveloped formal logical reasoning as it fails to act as a cognitive unit, a unit of genuine cognition. In the same meaning, a concept cannot but "ascend" to a notion, as it will not reflect all the variety of actually existing connections and relations in the surrounding world, not form a genuinely objective cognitive worldview. In other words, an individual cognitive world will fail to correspond to the cultural world in which an individual lives and interacts.

The cognitive worldview develops not outside but via speech activity that ensures an individual's interaction with the surrounding world. In this regard, a cognitive worldview reflects in the language worldview of various native speakers, and the point where those two meet is a formed sphere of concepts. The sphere of concepts means systematized understanding of the surrounding world in connections and relations that is verbalized through language units having a high degree of generalizing essential, specific and individual features of objects and phenomena that constitute the surrounding world.

It is evident that, in the first approximation, a concept is not every word but a word corresponding to a notion, a logically formalized thought of the general essential features, connections, and relations between objects and phenomena of the surrounding reality. This does not mean that any word cannot be studied as a concept; this means that a studied word may not be a concept. A concept is a unit of thinking and at the same time a language unit that contains intellectual ways of conceptualizing a word in a collapsed view. This understanding does not contradict the definition of a concept proposed by Zalevskaya, which is accepted under certain conditions and with certain reservations. For example, Zalevskaya understands a concept as "a basic perceptive-cognitive-affective formation of a dynamic nature functioning spontaneously in the cognitive and communicative activity of an individual that follows the regularities of a person's mental life and because of this differs in a number of ways from notions and meanings as products of scientific description within the context of the linguistic theory" [6]. A concept differs from notions in its immaturity during the process of its formation and is justly named by Zalevskaya "a construct" as a perceptive-affective principle prevails in the formed pre-concept and allows, through the realized attitude towards acquired knowledge, including such knowledge in the forming sphere of concepts. Yet this circumstance does not necessarily mean that, in development of the individual's thinking and speech activity, a construct does not advance towards a notion as a unit of scientific cognition of the world. The conditions of a person's social involvement may notfurther such advancement but this circumstance does not cancel the general law of comprehending units of the individual lexicon as denotations and significations.

The modern cognitive linguistics disapproves of identifying concepts with notions, though studies of this phenomenon started with such identification. When enunciating a conceptual framework of the incipient cognitive linguistics, Askoldov (Alekseyev) expressly declared that "the issue of the nature of general notions of concepts (universals, according to the medieval terminology) is an old issue that has long been on a waiting list but whose core item has yet to be touched" [7]. Solomonik also believes that a mature concept is "an abstract scientific notion developed on the basis of a concrete real-life notion", that is, a mature formation generated during the process of development [8].

According to Karassik, "this approach corresponds to the position of Katznelson, S.D., who opposed formal notions to content-related ones; the former can be compared to everyday knowledge and are recorded in common dictionaries, while the latter can be compared to scientific knowledge and are defined in encyclopedic references" [9]. Karassik proposes a deep observation of Katznelson's characteristics of a concept - "The model 'representation - notion' accepted in the cognitive linguistics is specified in such case as 'representation common notion - notion - scientific notion'. The difference between a common notion and a scientific one lies in the random generalization of one's own experience at the level of a common notion and using deduction and induction at the level of a scientific notion" [9]. According to Karassik, Katznelson defines as concepts the intra-level formations, which are no longer representations but which 
have not become notions yet. In our opinion, what is more important in this regard is the acceptance of development of concepts as units of accumulating and storing cognitive experience performed by capabilities of different types of thinking. Here concepts serve as means and corresponding types of thinking - as ways of forming and developing a cognitive worldview in general and the sphere of concepts in particular.

The idea of the content of concepts vs. the type of thinking can be observed in definitions proposed by a great many scientists. Lyapin believes that concepts are specific self-forming integrative functional and system multi-dimensional (or at least three-dimensional) idealized formations that are based on the notion or pseudo-notion basis [10]. Slyshkin singles out "formed" and "forming" concepts and designates such feature of this mental formation as "variability", thus proposing for discussion the idea that the content of a concept depends on the type of thinking on the basis of which it is formed. Of particular attention is the division of concepts into concepts proper and metaconcepts that are formed as a result of comprehending the primary products of conceptualization [11].

The modern cognitive linguistic theory already contains endeavors to identify types of concepts based on genuine cognitive grounds. So far, such endeavorsare not linked directly to Vygotsky's theory as the inversion of the cognitive theory. In this regard, we consider distinguished types and kinds of concepts from the point of view of the main development stages of the thinking and speech mechanism [12].

For example, Karassik divides concepts into gestalts, frames, concepts proper, and notions. According to Karassik, a concept-gestalt is a subject matter of psychology, a frame is a subject matter of all cognitive sciences, a concept proper is a subject matter of cultural and linguo-cultural studies, while a notion is "a clot of the rational part of a concept, that is, that content including only essential characteristics of an object and is thought rationally, not experienced" [8].

This characteristic of a notion does not correspond to the point of view presented by Rubinshtein, who characterized conscience in an imaginative way as experiencing knowledge during its acquisition. At the moment it is acquired, a notion is a psychic phenomenon, and "every psychic phenomenon is differentiated from others and is defined as a such and such emotional experience due to the fact that is it an emotional experience of such and such; its internal nature is identified through its relation to the external" [13]. It is obvious that, from Rubinshtein's point of view, all kinds of concepts identified by Karassik can be the subject matter of any science he listed.

A gestalt is understood as an integral, mainly nonstructured image of an object or phenomenon that during the process of a person's development and selfdevelopment ascends to a frame, which, according to Vygotsky's typology, is a pre-notion. In other words, the classification of concepts proposed by Karassik corresponds to Vygotsky's ontogenesis of thinking and speech.
The classification of concepts based on cognitive grounds is described in the works of Shvedova, Babushkin, Boldyrev, Alefirenko, Popova, Sternin et al.

Based on the content-richness of the realized generalizations, Shvedova divides concepts into "big", "great", "basic", "major" and "small", "non-basic", "minor". According to Vygotsky's theory, such concepts are assigned in the process of developing pre-conception and conception thinking, and the relations between types of concepts in the process of their acquisition by speakers of a certain language are assigned in the logic of movement within the formed generalization grid.

Babushkin [14] proposes separating the following types of concepts: cognitive images, schemes, hypernyms, frames, insights, scenarios, and kaleidoscopic concepts. Based on the content-related characteristics of the above types of concepts, the logic of their establishment and development is viewed as follows.

At the level of complex, or common thinking, the following types can be formed -both cognitive images (the aggregate of images within the collective or individual conscience of people) and concepts-scenarios that are schemes of events, that is, scenarios of events in stereotyped episodes. Such types of concepts or, rather, pre-images of concepts are formed on the basis of complex thinking as they perform the main function of this type of thinking - accumulating and storing the experience of exploring the surrounding world. Here the real generalization is replaced with the processes of generalization, which do not include conscious analysis and systematization of the accumulated experience or the cognitive worldview. Generalization occurs as stereotypization of events, phenomena and cognitive operations that accompany the process of forming an idea of those. Stereotypization facilitates the transformation of the continuum world into the discrete one in people's minds and to a certain degree lays the basis for developing the formal and logical generalization.

At the level of formal and logical (pre-conceptual) reasoning, concepts-frames and concepts-hypernyms (and, in the first approximation, insights) can be and are formed. Concepts-frames are based on scripts but unlike the latter, frames are models of events and phenomena built on the basis of formal logical generalization. Identifying the criteria of experience generalization allows distracting oneself from the process of evaluating the accumulated experience and concentrating on identifying the main features of objects and phenomena and their interrelations. These processes form the basis of developing concepts-hypernyms understood as definitions without connotations.

A conscious attitude towards systematizing the accumulated experience, which is the main purpose of formal logical reasoning, leads to developing insights formations that mark sudden understanding or grasping particular relations and the structure of the situation in general. Insights are prototypes of notions that are formedthrough the possibilities of conceptual (theoretical) thinking. Intermediate mental formations are kaleidoscopic concepts, which are defined by Babushkin as products of metaphoric comprehension of the surrounding world unfolding either as cognitive images, 
or as a frame, a scheme, or scenario. Kaleidoscopic concepts confirm that concepts develop on the basis of different types of thinking, and, consequently, that the specific nature resulting from the main way of reflecting the surrounding world should find its place in the methodology of concept studies.

Classifications of Boldyrev, on the one hand, and Popova and Sternin, on the other hand, correspond in many ways. Boldyrev separates nine types of concepts: a non-abstract sensory image, representation, a scheme - a cognitive example of an object or phenomenon having a space and contour nature; a notion, a prototype, a propositional structure, or a proposition, a frame, scenarios, or scripts, and a gestalt [15]. A shortened version of this classification is presented in the works of Popova, \&Sternin [16]. They separate a conceptrepresentation, a concept-scheme, a concept-notion, a concept-frame, a concept-scenario, and a concept-gestalt.

Alefirenko separates the following types of linguocultural concepts: a representation, which is a concept completely formed by generalizing the sensory perception of the surrounding world, whether real or imaginative; a gestalt, which is a cultural concept formed in an integral way combining sensory and rational cognition, and also combining the dynamics and the statics of the cognizable object; a frame, which is a cognitive structure forming the stereotypes of language conscience; and a scenario, or a script, which is a variety of the frame structure, a stereotyped episode occurring in space and time [17].

\section{Results and Discussion}

The authors of the classifications presented above consider a concept-gestalt as a product of higher-order conceptualization ("the higher level of abstraction") which is an integral functional reasoning structure ordering the variety of separate phenomena in the conscience and combining sensory and rational components in their unity and integrity. According to this interpretation, a gestalt is little or no different from a frame or a concrete-sensory image. Ordering separate phenomena in conscience occurs by means of schemes, notions, and prototypes. Gestalt psychology that developed this notion has not proposed any logically transparent methods of identifying and studying a gestalt. In this regard, introducing gestalt in the conceptual framework of cognitive science is unadvisable. In other respects, the proposed types of concepts correspond to the types identified by Babushkin:

Cognitive images $=\mathrm{a}$ concrete-sensory image, $\mathrm{a}$ representation;

A concept-scheme $=$ a scheme, a propositional structure, or a proposition (a model of a certain area of experience), a frame, scenarios, or scripts.

The characteristics of an insight to a certain degree conform to the characteristics of a gestalt, except for the fact that the latter lacks the feature of heuristicity. A notion, unlike a gestalt, is considered to have no connection to the higher levels of abstraction, perhaps due to the absence or, rather, concealment of the affective component of the comprehension process.
The work V.S. Mes'kov. A.A Mamchenko [18] is characteristic of the cognitive subject type of causationinternal motivation for cognitive activity. The definition of cognitive activity as meta-activity, which is based on the cycle of transformation of the subject, presented as a process that connects the subject, environment, content, object and meta-levels of the information world.

Aligning the types of concepts in the logic of the cognitive process does not cancel the necessity to decide whether concepts are units of thinking and/or conscience or whether such formations should be considered products of cognitive activity or they contain the ways of implementing this activity. The problem of the concept expression in language and its non-verbalization is not solved either.

According to the logic of the theoretical foundations of developing the sphere of concepts that we propose, the concepts proper, within the process of their acquisition by native speakers of certain languages, are quite diverse. Regarding their formation on the basis of complex thinking, pre-concepts can be formations, which are not expressed in language and non-verbalized, but still act as means of forming and phrasing a thought, first of all, in the inner speech (a concrete-sensory image, a representation). During the period of developing a sphere of concepts based on formal logical reasoning, concepts are simultaneously units of cognition and objects of cognition. In other words, during the stage of concept development within formal logical reasoning, concepts also become units of conscience due to which the objectivized cognitive worldview is formed. At this stage, pre-concepts become expressed in language, and their verbalized nature ensures both the possibility to present them in speech and to study them. During the stage of improving the sphere of concepts based on conceptual thinking, concepts act as a means, a product, and a way of thinking. The existence of pre-concepts and concepts determines the existence of the naïve worldview and the scientific worldview, which constantly interact and influence one another substantially.

\section{Conclusion}

The concept as presented herein is a cognitive instrument, a means to form a cognitive worldview in general and a sphere of concepts in particular. A respective type of thinking and generalization provides cognitive instruments to concepts as they are formed. At the conceptual level of thinking, a concept not only combines essential, specific single features of objects and phenomena, but also contains a mental means of forming itself. As mental images and projections ascend to notions, the affective part of the cognitive process is not lost but is "hidden" in the way of constructing notions that is revealed within the cognitive process. Concepts can be studied along two vectors: from concepts-images to notions and from notions (including scientific categories) to mental images and projections. In our opinion, particular value here belongs to insights that uncover the specific nature of formation and development of the cognitive worldview. 
A concept is a unit of thinking and conscience that reflects the surrounding world in the formations corresponding to the most developed type of thinking.

We believe that solving the discussion regarding the existing approaches to concept studies will allow the cognitive linguistics in particular and cognitive science in general to return to analyzing these phenomena within the existing cognitive theory and proceed with a detailed study of types and kinds of forming and formed concepts.

\section{References}

1. L.S. Vygotsky, Thinking and Speech. In Selected Psychological Studies (Moscow, 1956)

2. S.G. Vorkachev. Happiness as a Linguo-Cultural Concept (Gnozis, Moscow, 2004)

3. V.V. Davydov. Types of Generalization in Education (Pedagogika, Moscow, 1972)

4. N.I. Zhinkin, Speech as Conductor of Information. (Nauka, Moscow, 1982)

5. I.A. Zimnyaya. Psychological Aspects of Education of a Person Speaking a Foreign Language: A Teaching Guide to High-School Teachers (Prosveshcheni, Moscow, 1978)

6. A.A. Zalevskaya. Psycho-Linguistic Approach to the Problem of Concept. In Methodological problems of Cognitive Linguistics (Voronezh, 2001)

7. S.A. Askoldov. Concept and Word. In Russian Literature. From the Theory of Literature to the Structure of the Text. The Anthology, 267-279. Moscow (1997)

8. A. Solomonik. Semiotics and Linguistics (Molodaya Gvardiya, Moscow, 1995)

9. V.I. Karassik. A Language Circle: Person, Concepts, Discourse (Peremena Volgograd, 2002)

10. S.Kh. Lyapin. Conceptology: To Establishing The Approach. In Concepts. Scientific Works of Center of Concepts 1, 11-35 (Arkhangelsk, 1977)

11. G.G. Slicking. Linguo-Cultural Concepts and Metaconcepts (Doctoral Thesis) (Volgograd, 2004)

12. O.V. Gnevek. Theoretical Foundations of SelfImproving Speech-Thinking Mechanism Formation. Concept, 1 (2013)

13. S.L. Rubinshtein. Basics of General Psychology (PiterKom, St. Petersburg, 1998).

14. A.P. Babushki. Types of Concepts in the Lexical and Phraseological Semantics of language. (Publishing House of the Voronezh State University, Voronezh:, 1996)

15. N.N. Boldyrev. Cognitive Semantics: A Course of Lectures on English Philology (Tambov, 2002)

16. Z.D. Popova, I.A. Sternin. Semantic and Cognitive Language Analysis (Istoki, Voronezh, 2007)

17. N.F. Alefirenko. Poetic Energy of the Word. The Synergetics of Language, Consciousness, and Culture (Academia, Moscow: 2002)
18. V.S. Mes'kov, A.A. Mamchenko, Questions of philosophy 10 (2010) 